\title{
Evidence that aberrant protein metabolism contributes to chemoresistance in multiple myeloma cells
}

\author{
RICHARD K. SIPES, XUE XIA, BRIAN S. LEWIS and NICHOLAS E. BURGIS \\ Department of Chemistry and Biochemistry, Eastern Washington University, Cheney, WA 99004, USA
}

Received December 16, 2011; Accepted January 27, 2012

DOI: $10.3892 /$ or.2012.1716

\begin{abstract}
Multiple myeloma (MM) is an incurable B lymphocyte cancer. To date, a comparative analysis of global protein metabolism for the MM cell line CCL-155 (RPMI-8226) and the non-cancerous B lymphocyte cell line CCL-156 (RPMI-1788) has not been published. Here, we report that both global protein synthesis and degradation occur at a higher rate in MM cells and demonstrate that alkylating agents can reduce global protein degradation in both cell lines, but the effect is greater in CCL-156 cells. Treatment with melphalan plus the proteasome inhibitor MG132 reduced global protein degradation for MM cells to roughly $60 \%$ of that seen without drugs, but the reduction was approximately three times greater for CCL-156 cells. This drug combination was growth inhibitory for both cell lines, but CCL-156 inhibition was 2-fold greater than that of the MM cell line. Additionally, treatment with melphalan plus the lysosomal inhibitor chloroquine did not affect growth of MM cells more than melphalan alone, whereas this combination drastically inhibited growth of CCL-156 cells despite protein degradation being maintained at $60 \%$ level for both cell lines. This suggests that a lysosomal function other than protein degradation is required for recovery from alkylation damage in CCL-156 cells. In general, CCL-156 cells were affected to a greater extent for both protein degradation and growth inhibition with most drug combinations tested. Statistical analysis of our data $(\mathrm{P}=0.066)$ provides evidence that aberrant proteasome-mediated protein degradation correlates with chemoresistance in MM cells, but that lysosome-mediated protein degradation does not.
\end{abstract}

\section{Introduction}

In the last few years proteasome inhibitors such as bortezomib (PS-341 or Velcade) have emerged as important chemothera-

Correspondence to: Dr Nicholas E. Burgis, Department of Chemistry and Biochemistry, 226 Science Building, Eastern Washington University, Cheney, WA 99004, USA

E-mail: nburgis@ewu.edu

Key words: melphalan, multiple myeloma, proteasome inhibitors, protein degradation, chemoresistance peutic tools to treat multiple myeloma (MM) due to their ability to modulate the ubiquitin-proteasome system (1-5). Recent, clinical trials have resulted in very high complete recovery rates and increased rates of remission and longevity for a cohort of elderly MM patients when the proteasome inhibitor bortezomib was added to the classical regimen of melphalan (Alkeran) plus prednisone (6). The FDA approved the use of Velcade in the treatment of MM in 2003 (7), although the molecular mechanism for the enhanced anticancer activity has not been defined $(2,3,8)$.

Bortezomib is a potent and selective inhibitor of the proteasome, the major site of protein degradation in human cells (9). The proteasome is a large multi-subunit protein complex that is localized in the cytoplasm and nucleus and has multiple sites to rapidly degrade ubiquitinated proteins in a highly regulated and selective manner. The proteasome has many disparate roles in cell metabolism including cell signaling, DNA repair, transcription, cell adhesion and angiogenesis $(1,3,10,11)$. Bortezomib has been shown to induce apoptosis by inhibiting transcription factor $\mathrm{NF}-\kappa \mathrm{B}$ activation. However, this activity alone cannot fully explain the anticancer activity of bortezomib $(2,12)$.

Alkylation damage to DNA by melphalan can block DNA replication (13). Numerous studies have established a strong link between DNA repair and the proteasome and it can be surmised that a fully functional proteasome is essential for recovery after exposure to DNA damaging agents (14-19). In fact, proteome protection has been shown to be crucial for cell survival after exposure to radiation (20). Additionally, protein adduct formation after melphalan exposure has been observed and quantification of protein adducts has been proposed as a method to monitor chemotherapeutic toxicity and mutagenicity in patients $(21,22)$.

The proteasome and the vacuole (an organelle analogous to the lysosome in mammals) are the two major sites of protein degradation in yeast (23). We have recently demonstrated in yeast that global protein degradation is modulated after exposure to a broad range of DNA damaging agents including the $\mathrm{S}_{\mathrm{N}} 2$ alkylating agent methyl methanesulfonate (MMS) (17). Our results have established a role for both the proteasome and vacuole in recovery after exposure to MMS. These experiments identified the regulation of protein degradation as a critical factor for determining cell fate after exposure to DNA damaging agents. Thus, the molecular mechanism for the anticancer activity in MM patients treated with melphalan 


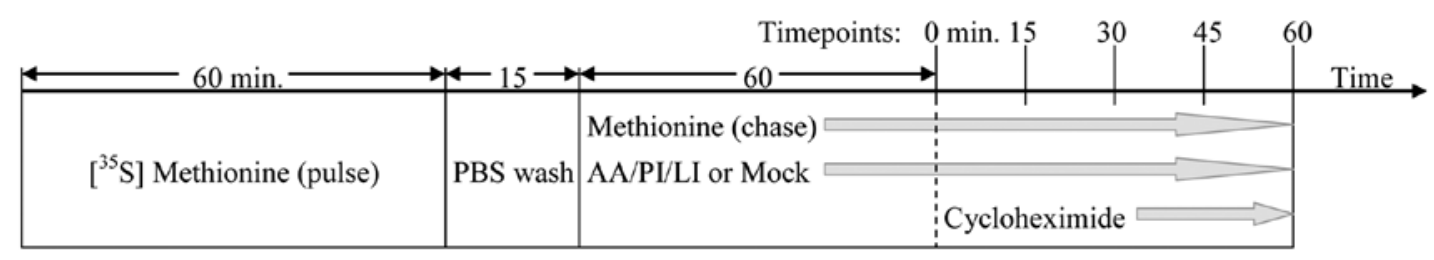

Figure 1. Protein degradation assay time-course outline. AA, alkylating agent; PI, proteasome inhibitor; LI, lysosome inhibitor.

and bortezomib may involve perturbation of global protein metabolism.

Like the proteasome, the lysosome is responsible for degrading proteins in the cell. However, the lysosome is responsible for bulk turnover of proteins by the non-selective process of autophagic uptake (23-26). The lysosome is also known to be involved in the activation of apoptotic pathways (27-29), causing cell death by necrosis and the upregulation of the autophagic pathway can lead to autophagic cell death $(30,31)$. Therefore, drugs such as chloroquine, which inhibits lysosome-mediated protein degradation, have become of interest in cancer research (32-36).

In this study, we investigate the differences in protein metabolism between a MM cell line (CCL-155) and a noncancerous B lymphocyte cell line (CCL-156). These two cell lines were derived from the peripheral blood of male patients by the same researcher during the same time period $(37,38)$. We observed that both protein synthesis and degradation occurred at a higher rate in CCL-155 cells. We demonstrated that alkylating agents can reduce the level of global protein degradation in both cell lines, but that CCL-156 cells are affected to a greater extent. Our data establish that growth inhibition of MM cells from the combined exposure to melphalan and proteasome inhibitors does not result from a gross reduction in global protein degradation. Using a drug cocktail containing both chloroquine and proteasome inhibitor we present evidence that protein metabolism in MM cells is aberrant and propose that this metabolic state contributes to chemoresistance.

\section{Materials and methods}

Cell lines, culture media and materials. Melphalan (MP Biomedicals, Solon, OH) and MG-132 (EMD Chemicals, Gibbstown, NJ) were dissolved in DMSO (Sigma-Aldrich, St. Louis, MO) at a stock concentration of $10 \mathrm{mM}$. Chloroquine (MP Biomedicals) was dissolved in $\mathrm{H}_{2} \mathrm{O}$ to the same concentration and all solutions were stored at $-20^{\circ} \mathrm{C}$. Methyl methanesulfonate (MMS) was purchased from Acros Organics (Geel, Belgium). CCL-155 (RPMI-8226) and CCL-156 (RPMI-1788) cell lines (ATCC, Manassas, VA) were maintained and assayed in untreated sterile tissue culture flasks or plates containing RPMI-1640 media supplemented with 20\% FBS (HyClone, Logan, UT) and $100 \mathrm{U} / \mathrm{ml}$ penicillin and $100 \mu \mathrm{g} / \mathrm{ml}$ streptomycin (MP Biomedicals) in a humidified incubator at $37^{\circ} \mathrm{C}$ with $5 \% \mathrm{CO}_{2}$ (standard conditions). Both cell lines were maintained at a density of $0.50-2.0 \times 10^{6}$ cells $/ \mathrm{ml}$ under sterile conditions. Prior to each assay, cell density and viability was determined using Trypan Blue (Alfa Aesar, Ward
Hill, MA) dye exclusion with triplicate measurements. Dead cells were excluded from the investigation. Viabilities between 80-95\% were typical for both cell lines.

Measurement of global protein synthesis. Our protocol for measuring global protein synthesis was adapted from the protocols of Pong et al (39) and Mans and Novelli (40). Cultures of CCL-155 and CCL-156 cells were incubated under standard conditions until the cell density reached $\sim 1 \times 10^{6}$ cells $/ \mathrm{ml}$. Both cell lines were processed simultaneously in the following manner. Cultures $(5 \mathrm{ml})$ were resuspended in an equal volume of methionine-free RPMI media supplemented with $10 \mu \mathrm{Ci} / \mathrm{ml}$ L- $\left.{ }^{35} \mathrm{~S}\right]$-methionine $(>1,000 \mathrm{Ci} / \mathrm{mmol})$ (Perkin-Elmer, Boston, MA) and quickly mixed by pipetting. Aliquots $(60 \mu \mathrm{l})$ were immediately removed in duplicate and added to a Whatman No. 3MM chromatography $2.3 \mathrm{~cm}$ filter disk (zero time point) which was briefly dried with lightly compressed air for $15 \mathrm{sec}$. Next, the filter disks were placed in an ice-cold $10 \%$ trichloroacetic acid (TCA) (Sigma-Aldrich) bath for $60 \mathrm{~min}$ to allow intact proteins to precipitate onto the filter disk followed by a 30-min wash in an ice-cold 5\% TCA bath. The above steps were repeated for the 30 and 60 -min time points. Two untreated filter disks were placed in the 10\% TCA bath prior to the experiment and carried through the entire procedure to determine background counts per minute (CPM). Filter disks were collected, dried overnight, added to 5-ml scintillation fluid and subjected to scintillation counting with a Beckman 6500 scintillation counter. Relative CPM incorporated were calculated by averaging the duplicate CPM readings and subtracting both the background CPM and the zero time point CPM from each timepoint.

Measurement of global protein degradation. Our protocol for measuring global protein degradation was adapted from the protocols of Rock et al (41) and Meriin et al (42) (Fig. 1). Cultures of either CCL-155 or CCL-156 cells at $\sim 1 \times 10^{6}$ cells $/ \mathrm{ml}$ were resuspended in methionine-free RPMI media supplemented with $10 \mu \mathrm{Ci} / \mathrm{ml} \mathrm{L}-\left[{ }^{35} \mathrm{~S}\right]$-methionine and incubated under standard conditions for $1 \mathrm{~h}$. Next, cells were washed with phosphate-buffered saline (PBS) (MP Biomedicals) and resuspended in the same media with $0.2 \mathrm{mg} / \mathrm{ml}$ DL-methionine (Calbiochem, Los Angeles, CA). The culture was then split into separate 5 or $10-\mathrm{ml}$ cultures and preincubated with appropriate drugs or vehicle for $1 \mathrm{~h}$. Next, cycloheximide (MP Biomedicals) was added to each culture at a final concentration of $100 \mu \mathrm{g} / \mathrm{ml}$, and $450 \mu \mathrm{l}$ aliquots were immediately removed in duplicate and added to TCA (10\% final concentration) at appropriate time intervals. Samples were mixed by brief vortexing, placed on ice for $1 \mathrm{~h}$ 


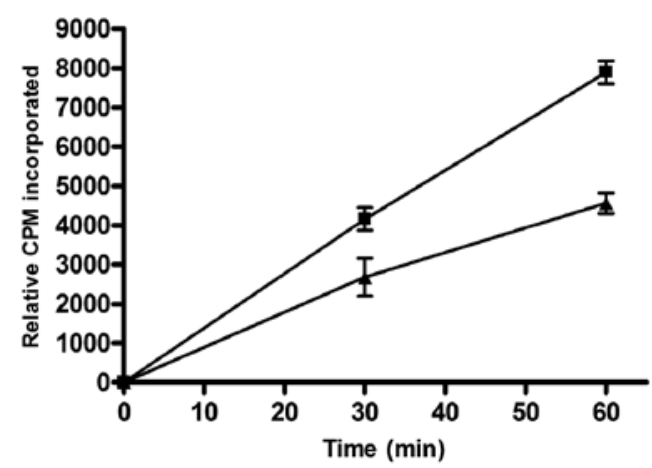

Figure 2. Protein synthesis profile for CCL-155 and CCL-156 cells. Actively growing cultures were incubated under standard conditions in methionine depleted RPMI media supplemented with L- $\left[{ }^{35}\right.$ S $]$-methionine. Aliquots were removed in duplicate every $30 \mathrm{~min}$, processed as outlined in Materials and methods and relative CPM incorporated was calculated. Data are plotted as the mean \pm SE of three independent experiments. $₫$, CCl-155; $₫$, CCL-156.

and centrifuged in a microfuge at maximum speed for $5 \mathrm{~min}$. Aliquots of supernatant were removed and subjected to scintillation counting with a Beckman 6500 scintillation counter. Percent degradation was calculated by averaging the duplicate CPM readings and using the following equation: \% degradation $=[($ Avg CPM time point X/Avg CPM time point zero $)-1]$ $\mathrm{x} 100 \%$. The increase in CPM detected in the supernatant corresponds to the release of free amino acids over time.

Cell proliferation test. Media was delivered to a 96-well plate so that the final volume, with drugs and cells included, would be $150 \mu \mathrm{l} /$ well. The drugs at $10-\mathrm{mM}$ stock concentrations were serially diluted with media so that delivering $15 \mu \mathrm{l}$ of drugs to a well would yield the appropriate working concentrations. Cells were diluted in media so that delivering $90 \mu \mathrm{l}$ would seed 7,500 cells/well. Media-only wells were included to determine background. The assay was incubated for $72 \mathrm{~h}$ under standard conditions in triplicate, and viability was determined using the CellTiter $96{ }^{\circledR} \mathrm{AQ}_{\text {ueous }}$ One Solution Cell Proliferation Assay (Promega, Madison, WI) according to the manufacturer's protocol. Absorbance (abs) was read using a Spectramax 250 Plate Reader (Molecular Devices, Sunnyvale, CA) at $490 \mathrm{~nm}$ to determine viability and $600 \mathrm{~nm}$ to determine non-specific abs. The $600 \mathrm{~nm}$ abs was subtracted from the $490 \mathrm{~nm}$ abs to obtain the adjusted abs. The adjusted abs for each treatment was averaged, and the average adjusted abs of media-only wells was deducted from the average adjusted abs of each treatment to obtain the final abs.

Statistical analysis. Statistical significance was determined using unpaired two-tailed Student's t-tests with a 95\% confidence interval using the built-in statistical analysis tool in the GraphPad Prism software program. Linear regression analysis was performed using Microsoft Office Excel 2007.

\section{Results}

Rates of global protein synthesis and degradation for the $C C L-155$ and $C C L-156$ cell lines. In general, we observed that protein metabolism occurred at a faster rate for the $\mathrm{MM}$ cell line, CCL-155, than the immortalized B-cell line, CCL-156

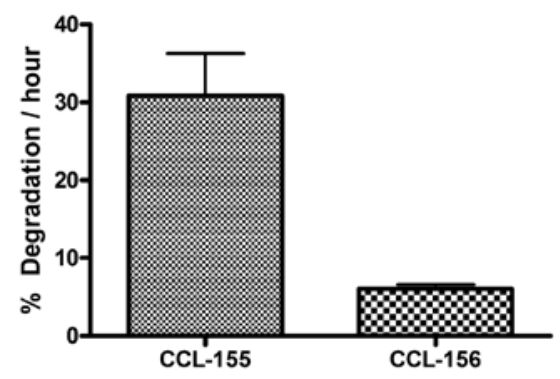

Figure 3. Percent protein degradation per hour for CCL-155 and CCL-156 cells. Actively growing cultures were incubated under standard conditions in methionine depleted RPMI media supplemented with L- $\left[{ }^{35} \mathrm{~S}\right]$-methionine for $1 \mathrm{~h}$. Cells were washed and resuspended in the same media with excess DL-methionine. Next, cells were incubated for $1 \mathrm{~h}$ and cycloheximide was added to each culture. Duplicate aliquots were removed immediately and $60 \mathrm{~min}$ later, processed as outlined in Materials and methods and percent degradation was calculated. Data are plotted as the mean \pm SE of three independent experiments.

(Figs. 2 and 3). To measure global protein synthesis, actively growing cultures were incubated with L- $\left[{ }^{35} \mathrm{~S}\right]-$ methionine. The level of protein synthesis was determined by measuring the amount of radioactivity incorporated into intact cellular proteins (Materials and methods). Fig. 2 indicates that protein synthesis for both cell lines is linear, and that the level of radioactivity incorporated into intact proteins reaches 7892 CPM on average for CCL-155 cells after 1-h incubation with $\left[{ }^{35} \mathrm{~S}\right]$-methionine, while the CCL-156 cells reach an average of 4563 CPM under the same conditions. At the 60-min time point the rate of protein synthesis for CCL-155 is about 1.7-fold greater than the rate for the CCL-156 cell line $(\mathrm{P}=0.001)$. This is consistent with transcriptional profiling data which showed that the genes involved in protein synthesis are upregulated in MM cells compared to normal plasma cells (43).

To measure global protein degradation, actively growing cultures were incubated (pulse) with L- $\left[{ }^{35} \mathrm{~S}\right]-$ methionine for $1 \mathrm{~h}$ followed by incubation (chase) with unlabelled methionine for $1 \mathrm{~h}$ (Fig. 1). Next, cycloheximide was added to stop protein synthesis, and duplicate aliquots were immediately removed and processed to determine the background level of radioactivity (time zero). After 1-h incubation in cycloheximide and unlabelled methionine duplicate aliquots were removed and processed. This methodology provided consistency with measurements made in the presence of drugs (see below).

Percent protein degradation was calculated relative to the level of radioactivity at time zero. For CCL-155 cells, we observed that about $30 \%$ of the cellular proteins had been degraded by $1 \mathrm{~h}$ (Fig. 3). This value is in good agreement with previous protein degradation measurements in human cell cultures $(41,44)$. Fig. 3 shows that the average rate of protein degradation was 5 times greater for CCL-155 cells $(\mathrm{P}<0.05)$, with CCL-156 cells degrading about $6 \%$ of the cellular proteins in $1 \mathrm{~h}$. It should be noted that the CCL-155 cells consistently grow at a slower rate than the immortalized CCL-156 cells (Fig. 4). Therefore, the differences we observed in protein metabolism cannot be attributed to a gross difference in intrinsic growth rates for these cell lines in culture.

Effect of an alkylating agent on global protein degradation. The above protein degradation protocol was followed, but 


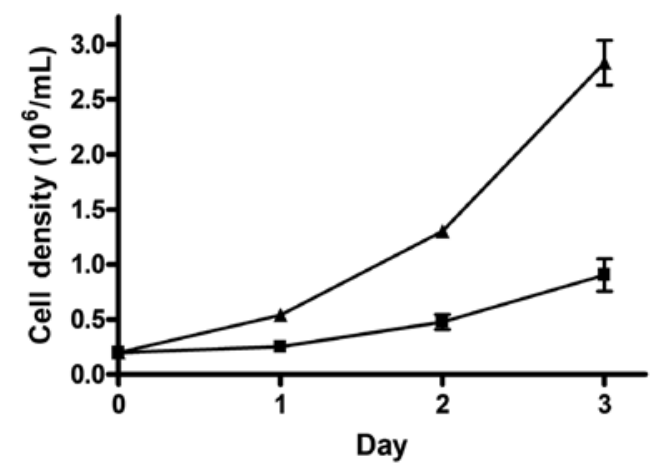

Figure 4. Growth curve for CCL-155 and CCL-156 cells. Actively growing cultures were diluted to $0.20 \times 10^{6}$ cells $/ \mathrm{ml}$ and incubated under standard conditions. Viable cell density was determined every $24 \mathrm{~h}$ over a 72 -h period from three independent measurements using trypan blue dye exclusion. Data are plotted as the mean \pm SE of three independent experiments. $\_, \mathrm{CCl}-155$; ^, CCL-156.

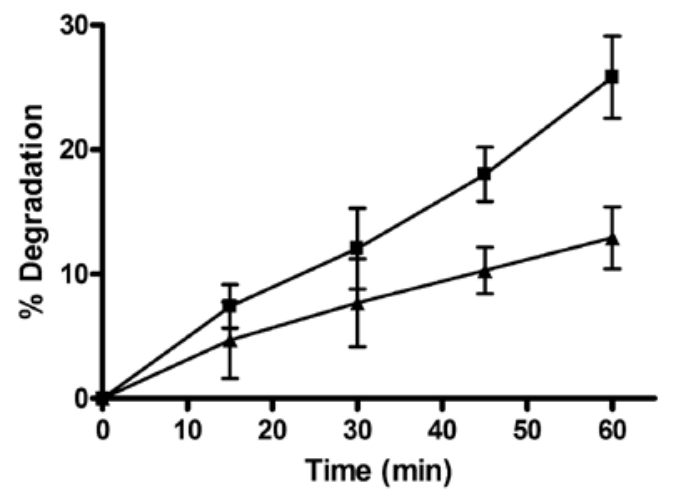

Figure 5. Protein degradation profile for CCL-155 cells treated with MMS or untreated. Cells were treated as in Fig. 3 with the following exceptions. After resuspending in media containing excess DL-methionine the culture was split and exposed to $0.05 \%$ MMS or untreated for $1 \mathrm{~h}$ prior to addition of cycloheximide. After addition of cycloheximide duplicate aliquots were removed every $15 \mathrm{~min}$ for $1 \mathrm{~h}$. Data are plotted as the mean $\pm \mathrm{SE}$ of at least three independent experiments.. , No MMS; $\mathbf{\Delta}, 0.05 \%$ MMS.

included addition of the alkylating agent MMS or mock at the beginning of the chase period; $1 \mathrm{~h}$ prior to the addition of cycloheximide (Fig. 1). This methodology allowed for radioactive labeling prior to dividing the cells for drug treatment, as well as one hour for expression of MMS-induced genes before inhibiting protein synthesis by cycloheximide. Addition of cycloheximide insures radioactive methionine will not be recycled. Fig. 5 indicates that global protein degradation is linear over this time period for treated and untreated CCL-155 cultures and that treatment with $0.05 \%$ MMS results in a significant decrease in the rate of protein degradation $(\mathrm{P}<0.05$ at $1 \mathrm{~h}$ ). This is a relatively low MMS dose compared to doses used for transcriptional profiling experiments for human cells (45). Nonetheless, this dose causes a 2-fold reduction in the rate of protein degradation compared to the untreated sample.

It is well known that the 3-methyladenine lesions that develop in DNA after MMS exposure can block replicative DNA polymerases (46); however, our observation suggest that the antiproliferative effects of alkylating agents may include the modulation of global protein degradation. It should

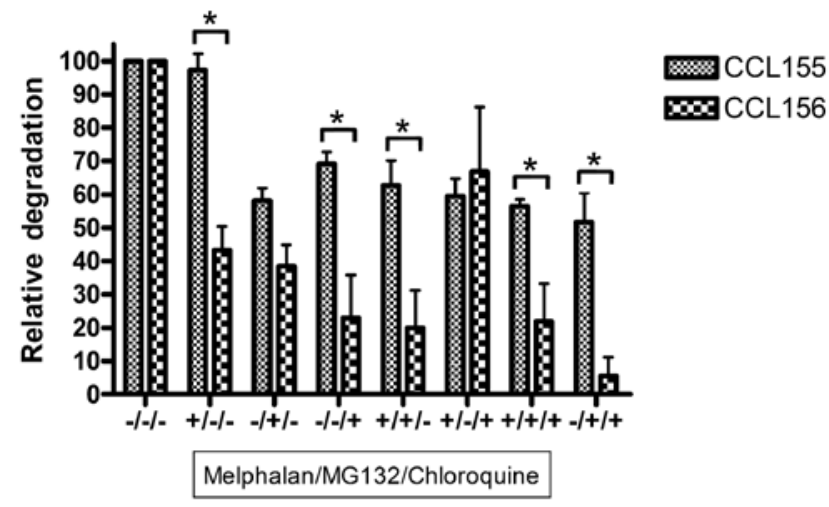

Figure 6. Protein degradation assay for CCL-155 and CCL-156 cells treated with combinations of melphalan, MG132 and chloroquine. Cells were treated as in Fig. 3 with the following exceptions. After resuspending in media containing excess DL-methionine the culture was split and exposed to appropriate drugs for $1 \mathrm{~h}$ at the following concentrations: melphalan, $500 \mu \mathrm{M}$; MG132, $50 \mu \mathrm{M}$; chloroquine, $1 \mathrm{mM}$. Data are plotted as the mean \pm SE of at least three independent experiments relative to the untreated culture. ${ }^{*} \mathrm{P}<0.05$.

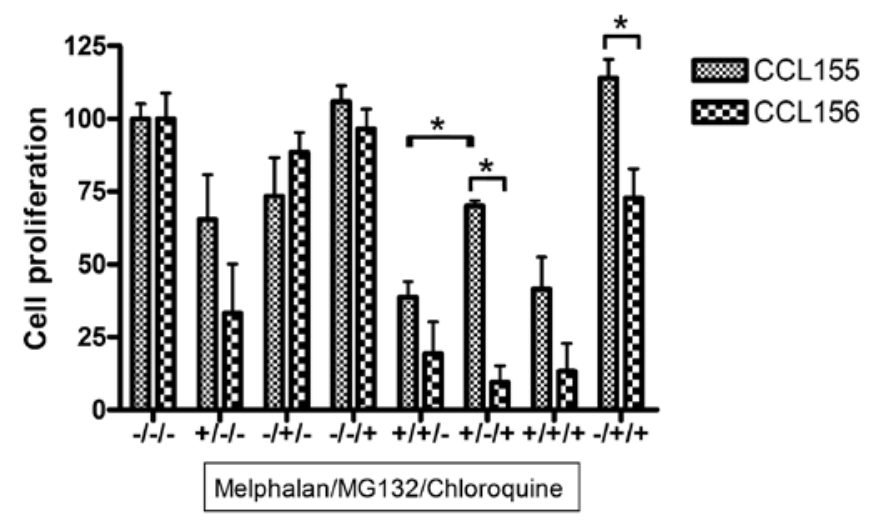

Figure 7. Cell proliferation test for CCL-155 and CCL-156 cells treated with combinations of melphalan, MG132 and chloroquine. Approximately 7,500 cells were seeded in a 96-well plate in triplicate and incubated under standard conditions in the presence or absence of drugs for $72 \mathrm{~h}$ and cell viability was determined. Melphalan, $5 \mu \mathrm{M}$; MG132, $0.2 \mu \mathrm{M}$; chloroquine, $5 \mu \mathrm{M}$. Data are plotted as the mean $\pm \mathrm{SE}$ of at least three independent experiments. ${ }^{*} \mathrm{P}<0.05$.

be noted that this result is in contrast to data obtained with yeast cells which showed that treatment with MMS actually increased the rate of protein degradation (17).

Global protein degradation is aberrant for CCL-155 cells. Next, we compared the effects of different drugs on the levels of global protein degradation for the CCL-155 and CCL-156 cell lines. Side-by-side comparisons of eight different drug treatments were performed as outlined in Fig. 1. For these assays, we used the clinically relevant alkylating agent melphalan, the proteasome inhibitor MG132 and the lysosomal inhibitor chloroquine. Proteasome and lysosome inhibitor concentrations were chosen based on literature values that yielded significant inhibition of protein degradation in human cells $(42,47-50)$. We chose a melphalan concentration that provided significant disparity in the effect on protein degradation between the two cell lines. Because acute drug treatment is required for this assay, we used a melphalan concentration much higher than what is clinically relevant. 
Table I. Percent difference in the average relative levels of protein degradation or cell proliferation between the CCL-155 and CCL-156 cell lines.

Treatment with melphalan/MG132/chloroquine

\begin{tabular}{lccccccr} 
& $+/-/-$ & $-/+/-$ & $-/ /+$ & $+/+/-$ & $+/ /++$ & $+/+/+$ & $-/+/+$ \\
\hline Protein degradation & $\mathbf{5 4 . 0}$ & $\mathbf{1 9 . 7}$ & 46.1 & $\mathbf{4 2 . 6}$ & -7.4 & $\mathbf{3 4 . 4}$ & $\mathbf{4 6 . 1}$ \\
Cell proliferation & $\mathbf{3 2 . 3}$ & $\mathbf{- 1 5 . 0}$ & 9.3 & $\mathbf{1 9 . 2}$ & 60.5 & $\mathbf{2 8 . 2}$ & $\mathbf{4 1 . 3}$ \\
\hline
\end{tabular}

Bold indicates correlation between protein degradation and cell proliferation $(\mathrm{P}=0.066)$.

Collectively, we observed that global protein degradation in CCL-155 cells is less affected by addition of drugs to the media. Fig. 6 indicates that addition of $500 \mu \mathrm{M}$ melphalan to the media results in a slight but insignificant decrease in the level of protein degradation for CCL-155 cells, but that the level of protein degradation for CCL-156 cells is reduced over $50 \%(\mathrm{P}<0.05)$. In general, treatment of CCL-155 with any drug combination, other than melphalan alone, resulted in a 30-50\% decrease in the level of protein degradation. Treatment with $50 \mu \mathrm{M}$ MG132 resulted in a roughly $50 \%$ reduction in the level of protein degradation for both cell lines. Treatment with $1 \mathrm{mM}$ chloroquine or melphalan plus MG132 caused the level of protein degradation for CCL-156 to be reduced at least twice as much as CCL-155 $(\mathrm{P}<0.05)$. Treatment with melphalan plus chloroquine had a similar effect on the level of protein degradation for both cell lines. Treatment with all three drugs reduced the level of protein degradation in CCL-156 about twice as much as the levels in CCL-155 $(\mathrm{P}<0.05)$. Treatment of cells with MG132 plus chloroquine reduced protein degradation in both cell lines, but the level of protein degradation for CCL-156 cells was drastically reduced to about $5 \%$ of the level for untreated CCL-156 cells. This level of protein degradation is approximately 10-fold less than that observed for similarly treated CCL-155 cells $(\mathrm{P}<0.05)$. For most drug treatments, we observed a statistically significant difference in the level of protein degradation between CCL-155 and CCL-156 cells. This indicates that global protein degradation is grossly aberrant in CCL-155 cells.

CCL-155 cells are less sensitive to the growth inhibition effects of various drug cocktails. The effects of different combinations of melphalan, MG132 and chloroquine on cell proliferation were investigated. Drug concentrations were chosen which caused no greater than $30 \%$ average growth inhibition for CCL-155 cells when administered alone.

In general, CCL-155 cells were less sensitive to growth inhibition by these drug combinations than CCL-156 cells (Fig. 7). For instance, treatment with melphalan alone, melphalan plus MG132 or melphalan plus chloroquine resulted in at least a 2-fold difference between cell lines for average cell proliferation with these drug combinations exerting more growth inhibition in CCL-156 cells. No discernable differences were observed with either MG132 or chloroquine alone, and growth inhibition with these treatments was minimal in both cell lines. However, combination of MG132 plus chloroquine proved to be growth inhibitory only for CCL-156 $(\mathrm{P}<0.05)$.
Finally, treatment with all three drugs greatly inhibited cell proliferation in both cell lines with CCL156 cells exhibiting a 3 -fold lower average cell proliferation than CCL-155 cells. It should be noted that the highest degree of growth inhibition for CCL-155 cells was achieved only with combined exposure to melphalan plus MG132, consistent with clinical use of this drug combination to treat MM (6).

Statistical support for a correlation between proteasomemediated protein degradation and cell proliferation. For several drug treatments, we noticed that differences in the relative protein degradation between the cell lines often corresponded to similar differences in relative cell proliferation (comparing Figs. 6 and 7). Therefore, we sought to determine if there was a correlation between the level of relative global protein degradation and the relative level of cell proliferation for CCL-155 and CCL-156 cells. Our analysis included data points derived from treatments which included melphalan alone and MG132 in any combination. For this analysis, we took the average values for the relative level of protein degradation or cell proliferation and calculated the difference between CCL-155 and CCL-156 (CCL-155 minus CCL-156) for each treatment (Table I). We next plotted the differences for protein degradation versus the differences for cell proliferation. Using linear regression analysis with these five data points we obtained an $\mathrm{r}^{2}$ value of $0.7278(\mathrm{r}=0.8531)$. Next, we performed a Student's t-test assuming three degrees of freedom and obtained a P-value of 0.066 . This correlation was abolished when we considered treatment with chloroquine in the absence of MG132.

\section{Discussion}

Protein synthesis and degradation are thought to be ongoing processes in mammalian systems, and proteins are hypothesized to exist in a dynamic equilibrium within the cell (51). Our results show that the intrinsic rate of protein metabolism for the MM cell line CCL-155 is elevated compared to the non-cancerous B lymphocyte cell line CCL-156. Significantly higher rates were observed for both global protein synthesis and global protein degradation in CCL-155 cells (Figs. 2 and 3). It is well known that protein metabolism is elevated in a typical cancer cell (52-54); however, relatively speaking, MM is a slow growing cancer and this is reflected in cultured cells (Fig. 4). Therefore, considering cell doubling time, it can be extrapolated that global protein synthesis and degradation 
in CCL-155 is elevated roughly 4 -fold and 12 -fold per cell generation, respectively. The deficit in the rate of synthesis vs. degradation may in part explain the development of uremia in some MM patients (55).

Our measurements of global protein degradation revealed that CCL-155 did not have a significant change in the level of protein degradation after exposure to melphalan, whereas MMS caused a 2-fold reduction in protein degradation. The discrepancy between our results with melphalan and MMS can be explained by the fact that the melphalan concentration in our assays is roughly 10 -fold less than the MMS concentration. Furthermore, Lawley and Thatcher have determined that in vivo MMS preferentially alkylates proteins (56) whereas melphalan has equivalent reactivity with nucleic acids and proteins (57).

In contrast, exposure of CCL-156 cells to the same concentration of melphalan resulted in a greater than 2 -fold reduction of global protein degradation compared to untreated CCL-156 cells (Fig. 6). Additionally, melphalan was observed to be more toxic to CCL-156 cells (Fig. 7). Indicators of differences in protein metabolism and stress response phenotypes between MM cells and B cells can be found in the literature. For instance, transcriptional profiling experiments have shown that genes involved in the unfolded protein response, protein synthesis and the stress response are upregulated in patientderived MM cells compared to plasma cells derived from an unaffected twin (43). Additional experiments showed that $X B P 1$, which mediates the unfolded protein response, as well as a group of disulfide isomerase genes, is expressed at a higher level in CCL-155 than in mature B cells (58). Considering that global protein synthesis and degradation is increased in MM cells (Figs. 2 and 3), the data suggests that MM cells are better prepared to process and replace alkylation damaged proteins.

We primarily observed that cell line CCL-155 showed significantly higher levels of global protein degradation for varying combinations of melphalan, MG132 and chloroquine than cell line CCL-156. The most notable difference between CCL-155 and CCL-156 was observed when both the proteasome and lysosome were inhibited. The greatest growth inhibition for both cell lines was observed when melphalan plus MG132 were included in the drug cocktail even though the protein degradation level for CCL-155 remained at about $60 \%$ of the untreated level. The growth inhibition result with CCL-155 is consistent with a previous published study (4); however, it is surprising to observe that the non-cancerous cell line actually appears more sensitive to this drug combination. This observation may help explain the hematological toxicities and compromised immune responses observed in clinical trials (6). Importantly, our results establish that the sensitivity of CCL-155 to melphalan plus MG132 cannot be attributed to a gross reduction in protein degradation. Overall, we surmise that the increased rate of protein metabolism in CCL-155 cells renders this cell line less prone to modulation of protein degradation by proteasome inhibitors, lysosomal inhibitors and alkylating agents.

Several studies have identified both the proteasome and lysosome (or counterpart) to be important for recovery from DNA damaging agents (14-19). Our previous results in yeast showed that inhibition of proteasomal and vacuolar proteases inhibited growth in cultures treated with MMS (17). Here, we observe similar results with proteasome and lysosome inhibitors. One interesting result is observed when we treat cells with melphalan plus chloroquine. For this drug cocktail, protein degradation was reduced to about $60 \%$ of the untreated level for both cell lines, but this treatment proved much more effective at inhibiting growth for CCL-156. Chloroquineinduced destabilization of the lysosomal membrane has been shown to cause release of pro-death signals into the cytosol $(29,34,35)$. Differential destabilization of the lysosomal membrane between these cell lines may explain this observation. On the other hand, this result may indicate that a lysosomal function other than protein degradation is required for recovery from alkylation damage in CCL-156 cells such as the metabolism of damaged carbohydrates and/or lipids. Another interesting observation is that treatment of CCL-155 with melphalan plus chloroquine results in the same degree of growth inhibition as melphalan alone while treatment with melphalan plus MG132 is the most growth inhibitory treatment for CCL-155. Furthermore, exposure of either cell line to melphalan plus MG132 plus chloroquine does not increase growth inhibition compared to treatment with melphalan plus MG132 for either cell line. These data are consistent with studies in yeast where the proteasome proved to be the protein degradation machinery most important for recovery from alkylating agents (17).

Upon further analysis of our protein degradation and cell proliferation data, we find fairly good evidence for a correlation between the degree of protein degradation reduction and the degree of growth inhibition for treatments which include melphalan alone and MG132 in any combination (comparing Figs. 6 and 7, summarized in Table I). Statistical analysis of the data resulted in a P-value of 0.066 , which suggests that drug treatments that result in a greater reduction in protein degradation levels for CCL-156 compared to CCL-155 also result in greater growth inhibition for CCL-156 compared to CCL-155. This correlation was not observed when we also considered treatment with chloroquine in the absence of MG132, further indicating that the proteasome has a more prominent role in recovery from alkylating agents. Assuming the data obtained with the non-cancerous CCL-156 cell line to represent a normal response, these data infer that CCL-155 cells are resistant to pharmaceutical modulation of global protein degradation rates and that this phenotype contributes to the chemoresistance of MM cells. Our data provides new insight into the metabolic state of MM cells and is important to consider as new therapies are developed to treat MM.

\section{Acknowledgements}

We wish to thank the Department of Biology and Department of Chemistry and Biochemistry at Eastern Washington University for shared use of supplies, equipment and facilities, Michael J. Kesling for assistance with the statistical analysis, Jon M. Gallion for capable technical assistance, and James Bugni for critical reading of the manuscript. Funding for this research was provided by a EWU Foundation Start Something Big Grant, a 2008 and 2009 EWU Faculty Grant for Research and Creative Works and grant 10BGIA4370060 from the American Heart Association-Pacific Mountain Affiliate awarded to N.E.B. 


\section{References}

1. Hideshima T, Mitsiades C, Akiyama M, et al: Molecular mechanisms mediating antimyeloma activity of proteasome inhibitor PS-341. Blood 101: 1530-1534, 2003.

2. Hideshima T and Anderson KC: Molecular mechanisms of novel therapeutic approaches for multiple myeloma. Nat Rev Cancer 2: 927-937, 2002 .

3. Hideshima T, Richardson $\mathrm{P}$, Chauhan $\mathrm{D}$, et al: The proteasome inhibitor PS-341 inhibits growth, induces apoptosis, and overcomes drug resistance in human multiple myeloma cells Cancer Res 61: 3071-3076, 2001.

4. Ma MH, Yang HH, Parker K, et al: The proteasome inhibitor PS-341 markedly enhances sensitivity of multiple myeloma tumor cells to chemotherapeutic agents. Clin Cancer Res 9: $1136-1144,2003$.

5. Driscoll J, Burris J and Annunziata CM: Novel strategies in the treatment of multiple myeloma: from proteasome inhibitors to immunotherapy. J Cel Sci Therapy 1:101, 2010.

6. Mateos MV, Hernandez JM, Hernandez MT, et al: Bortezomib plus melphalan and prednisone in elderly untreated patients with multiple myeloma: results of a multicenter phase $1 / 2$ study. Blood 108: 2165-2172, 2006

7. Kane RC, Bross PF, Farrell AT and Pazdur R: Velcade: U.S. FDA approval for the treatment of multiple myeloma progressing on prior therapy. Oncologist 8: 508-513, 2003.

8. Smith L, Lind MJ, Drew PJ and Cawkwell L: The putative roles of the ubiquitin/proteasome pathway in resistance to anticancer therapy. Eur J Cancer 43: 2330-2338, 2007.

9. Voorhees PM and Orlowski RZ: The proteasome and proteasome inhibitors in cancer therapy. Annu Rev Pharmacol Toxicol 46 189-213, 2006.

10. Mitsiades N, Mitsiades CS, Poulaki V, et al: Molecular sequelae of proteasome inhibition in human multiple myeloma cells. Proc Natl Acad Sci USA 99: 14374-14379, 2002.

11. Nawrocki ST, Bruns CJ, Harbison MT, et al: Effects of the proteasome inhibitor PS-341 on apoptosis and angiogenesis in orthotopic human pancreatic tumor xenografts. Mol Cancer Ther 1: $1243-1253,2002$.

12. Rajkumar SV, Richardson PG, Hideshima T and Anderson KC: Proteasome inhibition as a novel therapeutic target in human cancer. J Clin Oncol 23: 630-639, 2005.

13. Friedberg EC, Walker GC and Siede W: DNA Repair and Mutagenesis. ASM Press, Washington, DC, 1995.

14. Begley TJ, Rosenbach AS, Ideker T and Samson LD: Hot spots for modulating toxicity identified by genomic phenotyping and localization mapping. Mol Cell 16: 117-125, 2004

15. Gasch AP, Huang M, Metzner S, Botstein D, Elledge SJ and Brown PO: Genomic expression responses to DNA-damaging agents and the regulatory role of the yeast ATR homolog Meclp. Mol Biol Cell 12: 2987-3003, 2001.

16. Jelinsky SA, Estep P, Church GM and Samson LD: Regulatory networks revealed by transcriptional profiling of damaged Saccharomyces cerevisiae cells: Rpn4 links base excision repair with proteasomes. Mol Cell Biol 20: 8157-8167, 2000.

17. Burgis NE and Samson LD: The protein degradation response of Saccharomyces cerevisiae to classical DNA-damaging agents. Chem Res Toxicol 20: 1843-1853, 2007.

18. Workman CT, Mak HC, McCuine S, et al: A systems approach to mapping DNA damage response pathways. Science 312 : 1054-1059, 2006.

19. Jelinsky SA and Samson LD: Global response of Saccharomyces cerevisiae to an alkylating agent. Proc Natl Acad Sci USA 96: 1486-1491, 1999.

20. Krisko A and Radman M: Protein damage and death by radiation in Escherichia coli and Deinococcus radiodurans. Proc Nat Acad Sci USA 107: 14373-14377, 2010.

21. Tornqvist M, Fred C, Haglund J, Helleberg H, Paulsson B and Rydberg P: Protein adducts: quantitative and qualitative aspects of their formation, analysis and applications. J Chromatogr B Analyt Technol Biomed Life Sci 778: 279-308, 2002.

22. Noort D, Hulst AG and Jansen R: Covalent binding of nitrogen mustards to the cysteine-34 residue in human serum albumin. Arch Toxicol 76: 83-88, 2002

23. Wolf DH: From lysosome to proteasome: the power of yeast in the dissection of proteinase function in cellular regulation and waste disposal. Cell Mol Life Sci 61: 1601-1614, 2004.

24. Chiang HL, Schekman R and Hamamoto S: Selective uptake of cytosolic, peroxisomal, and plasma membrane proteins into the yeast lysosome for degradation. J Biol Chem 271: 9934-9941, 1996.
25. Ciechanover A: Intracellular protein degradation: from a vague idea, through the lysosome and the ubiquitin-proteasome system, and onto human diseases and drug targeting (Nobel lecture). Angew Chem Int Ed Engl 44: 5944-5967, 2005

26. Ciechanover A: Proteolysis: from the lysosome to ubiquitin and the proteasome. Nat Rev Mol Cell Biol 6: 79-87, 2005.

27. Guicciardi ME, Leist M and Gores GJ: Lysosomes in cell death. Oncogene 23: 2881-2890, 2004.

28. Jaattela M: Multiple cell death pathways as regulators of tumour initiation and progression. Oncogene 23: 2746-2756, 2004.

29. Cirman T, Oresic K, Mazovec GD, et al: Selective disruption of lysosomes in HeLa cells triggers apoptosis mediated by cleavage of Bid by multiple papain-like lysosomal cathepsins. J Biol Chem 279: 3578-3587, 2004

30. Fehrenbacher $\mathrm{N}$ and Jaattela M: Lysosomes as targets for cancer therapy. Cancer Res 65: 2993-2995, 2005.

31. Kroemer G and Jaattela M: Lysosomes and autophagy in cell death control. Nat Rev Cancer 5: 886-897, 2005.

32. Savarino A, Lucia MB, Giordano F and Cauda R: Risks and benefits of chloroquine use in anticancer strategies. Lancet Oncol 7: 792-793, 2006

33. Cooper RG and Magwere T: Chloroquine: novel uses and manifestations. Indian J Med Res 127: 305-316, 2008

34. Fan C, Wang W, Zhao B, Zhang S and Miao J: Chloroquine inhibits cell growth and induces cell death in A549 lung cancer cells. Bioorg Med Chem 14: 3218-3222, 2006.

35. Zhao H, Cai Y, Santi S, Lafrenie R and Lee H: Chloroquinemediated radiosensitization is due to the destabilization of the lysosomal membrane and subsequent induction of cell death by necrosis. Radiat Res 164: 250-257, 2005.

36. Fehrenbacher N, Gyrd-Hansen M, Poulsen B, et al: Sensitization to the lysosomal cell death pathway upon immortalization and transformation. Cancer Res 64: 5301-5310, 2004

37. Huang CC and Moore GE: Chromosomes of 14 hematopoietic cell lines derived from peripheral blood of persons with and without chromosome anomalies. J Natl Cancer Inst 43: 1119-1128, 1969.

38. Moore GE and Kitamura H: Cell line derived from patient with myeloma. NY State J Med 68: 2054-2060, 1968.

39. Pong SS, Nuss DL and Koch G: Inhibition of initiation of protein synthesis in mammalian tissue culture cells by L-1-tosylamido2-phenylethyl chloromethyl ketone. J Biol Chem 250: 240-245, 1975.

40. Mans RJ and Novelli GD: Measurement of the incorporation of radioactive amino acids into protein by a filter-paper disk method. Arch Biochem Biophys 94: 48-53, 1961.

41. Rock KL, Gramm C, Rothstein L, et al: Inhibitors of the proteasome block the degradation of most cell proteins and the generation of peptides presented on MHC class I molecules. Cell 78: 761-771, 1994.

42. Meriin AB, Gabai VL, Yaglom J, Shifrin VI and Sherman MY: Proteasome inhibitors activate stress kinases and induce Hsp72. Diverse effects on apoptosis. J Biol Chem 273: 6373-6379, 1998.

43. Munshi NC, Hideshima T, Carrasco D, et al: Identification of genes modulated in multiple myeloma using genetically identical twin samples. Blood 103: 1799-1806, 2004.

44. Fuertes G, Villarroya A and Knecht E: Role of proteasomes in the degradation of short-lived proteins in human fibroblasts under various growth conditions. Int J Biochem Cell Biol 35: 651-664, 2003

45. Islaih M, Li B, Kadura IA, et al: Comparison of gene expression changes induced in mouse and human cells treated with directacting mutagens. Environ Mol Mutagen 44: 401-419, 2004.

46. Larson K, Sahm J, Shenkar R and Strauss B: Methylation-induced blocks to in vitro DNA replication. Mutat Res 150: 77-84, 1985.

47. Matsuzawa Y and Hostetler KY: Inhibition of lysosomal phospholipase $\mathrm{A}$ and phospholipase $\mathrm{C}$ by chloroquine and 4,4'-bis(diethylaminoethoxy) alpha, beta-diethyldiphenylethane. J Biol Chem 255: 5190-5194, 1980 .

48. Wibo M and Poole B: Protein degradation in cultured cells. II. The uptake of chloroquine by rat fibroblasts and the inhibition of cellular protein degradation and cathepsin B1. J Cell Biol 63: 430-440, 1974

49. Nawaz Z, Lonard DM, Dennis AP, Smith CL and O'Malley BW: Proteasome-dependent degradation of the human estrogen receptor. Proc Natl Acad Sci USA 96: 1858-1862, 1999.

50. Sadiq F, Hazlerigg DG and Lomax MA: Amino acids and insulin act additively to regulate components of the ubiquitin-proteasome pathway in C2C12 myotubes. BMC Mol Biol 8: 23, 2007.

51. Moldave K: Intracellular protein metabolism in Ehrlich's ascites carcinoma cells. J Biol Chem 221: 543-553, 1956. 
52. Dang CV and Semenza GL: Oncogenic alterations of metabolism. Trends Biochem Sci 24: 68-72, 1999.

53. Heber D, Chlebowski RT, Ishibashi DE, Herrold JN and Block JB: Abnormalities in glucose and protein metabolism in non-cachectic lung cancer patients. Cancer Res 42: 4815-4819, 1982.

54. Plas DR and Thompson CB: Cell metabolism in the regulation of programmed cell death. Trends Endocrinol Metab 13: 75-78, 2002.

55. Moulopoulos LA, Granfield CA, Dimopoulos MA, Kim EE, Alexanian R and Libshitz HI: Extraosseous multiple myeloma: imaging features. AJR Am J Roentgenol 161: 1083-1087, 1993.
56. Lawley PD and Thatcher CJ: Methylation of deoxyribonucleic acid in cultured mammalian cells by $\mathrm{N}$-methyl-N'-nitro-Nnitrosoguanidine. The influence of cellular thiol concentrations on the extent of methylation and the 6-oxygen atom of guanine as a site of methylation. Biochem J 116: 693-707, 1970.

57. Osborne MR, Lawley PD, Crofton-Sleigh C and Warren W: Products from alkylation of DNA in cells by melphalan: human soft tissue sarcoma cell line RD and Escherichia coli WP2. Chem Biol Interact 97: 287-296, 1995.

58. Nakayama Y, Stabach P, Maher SE, et al: A limited number of genes are involved in the differentiation of germinal center $\mathrm{B}$ cells. J Cell Biochem 99: 1308-1325, 2006. 